\title{
(Un)settling Methodology: Walking the City of Memphis with Transcorporeality in a More-than- Human World
}

Wesam M. Salem, wsalem@memphis.edu

\begin{abstract}
In this paper, I explain how I engaged with walking as a sensory and relational inquiry that provoked thinking differently and intra-actively of research, and the entanglement (Barad, 2007) of our bodies with the space and matter. As I walked the city of Memphis, assemblages of my emplaced body movement, subjectivities, senses, feelings, and interactions with the materiality of the space deconstructed and interrogated the neoliberal normalized narratives of othering and belonging. Situating the walks within transcorporeality (Alaimo, 2012), transmateriality (Springgay \& Truman, 2017a), and the spactimematter entanglement (Haraway, 2015), I share how these walks generated three lines of flight (Deleuze \& Guattari,1987) that transformed my thinking of research methods and opened up spaces for new ways of knowing beyond the linear and the prescribed. The three lines of flight, I discuss in this paper, informed and shaped my thinking of: my research methods with respect to interviewing Muslim American youth, the embodied experience of walking within the entanglement of space time matter in a more-than-human world, and the concept of (dis)placed bodies within the postcolonial thought.
\end{abstract}

Keywords: walking research, transmateriality, transcorporeality, postcolonialism, Ziyyarah methodology

\section{Introduction}

I was introduced to walking methodologies as part of a special cross-disciplinary and cross-institutional graduate course at the University of Memphis. As we explored how bodies are (dis)placed by the intersections of inequality, race, social class, I realized that I am a (dis)placed body at the intersection of thought, research practices, and the politics of belonging. As an immigrant Middle Eastern American, head-covering Muslim woman, my skin, religion, gender, and language shove me to the margins and my 
body is (dis)placed as different. Conducting research with Muslim American students ${ }^{1}$ within the Western academia and the hostile sociopolitical sphere that viewed difference as threatening, I could not escape the (dis)placement of particular research practices. Western and colonial practices of interviews that viewed the subject as the sole source of knowledge and the researcher as the allknowing appeared to have little or no room for research methods outside the prescribed. In this paper, I share how my conceptualization of walking methodology evolved over the three walks I took that were guided by the readings that situated the walks. First, I situate the three walks I took in the Memphis neighborhood of Annesdale while I draw from the course readings. Then, I share three generative lines of flight (Deleuze \& Guattari, 1987) that informed my thinking of my research methods and deterritorialized thought, space, time, and matter. Following that, I discuss in this paper, how these lines of flight informed and shaped my thinking of my research methods with respect to interviewing Muslim American youth, the embodied experience of walking within the entanglement of space time matter in a more-than-human world, and the concept of (dis)placed bodies within postcolonial thought.

\section{Situating the Walks}

The course syllabus was far from the postpositivist syllabus I was accustomed to in graduate school. Mainly, it included directed readings, completing three walks in an identified neighborhood in urban Memphis, and completing "a project." The details on either one of these items were left for the students to generate and to think of within and with the course readings. Additionally, the course instructors requested the students to complete a blog post after each walk to reflect on their ontological commitment, positionalities, and how the intersectionality of each individual's race, gender, culture, ethnicity, and social class manifested within the space.

The instructors grouped us in groups of three each from different disciplines (e.g., education, art, and anthropology) as a way to generate multidimensional thinking of the walks. Out of six urban Memphis neighborhoods listed for us to choose, I rushed to suggest Annesdale simply because I have never visited that part of the city on foot and the group accepted. Later I learned that Annesdale is a historic neighborhood in urban Memphis with a commercial strip, industrial properties, and railroads along the northern and the western boundaries. Though it is a historic neighborhood, Annesdale is faced with issues of vacant properties and homes as well as increased crime rates. We took the first walk as a group, but for the second and the third, each of us walked alone. Walking as a group, we became aware of the possibilities of the walking methodology within which our positionalities and interaction with the materiality of the space.

It is worth mentioning that walking alongside each other (in our groups), our interactions and talk as we observed, engaged with, and made sense of our space alleviated some of the difference I felt. At the intersection of our race, gender, religion, and nationality, our walks eliminated invisible walls and

\footnotetext{
${ }^{1}$ My dissertation research focuses on conceptualizing how Muslim American students construct their mathematics identities within the context of Islamophobia. This research draws from previous research with other racialized student population particularly with African Americans.
} 
differences and brought to the fore human solidarity and sameness. The walk blurred boundaries of the unfamiliar and opened up the space for intimate and personal conversations.

\section{First Line of Flight}

The course readings of Braidotti (2011), Manning (2016), and Haraway (2015), for example, framed our walks and provoked a critique of the postpositivist research methods rooted in Western thoughts and sensibilities. Erin Manning (2016) argues that arts-based research, or what in Canada is called researchcreation, brought to the fore the question of methodology and how it incites and produces new knowledge. It "create[s] the conditions for new ways of encountering study-forms and forces of intellectuality that cut across normative accounts of what it means to know" (Manning, 2016, p. 27). During the time I read the Manning (2016) chapter that situated our first walk, I was in the process of writing the methodology section for my dissertation. Grappling with the question of qualitative methodology within my theoretical framework of postcolonialism, I began questioning my research method of interviews, my Western training, and how the postpositivist interviewing practices seemed an ill-fit with my non-Western participants and my postcolonial orientation of the study. I have found that the semi-prescribed interview process isolated my participants from their assemblages of space, time, and matter and rendered little to no insight on their cultural and social positonalities. Motivated by walking methodologies and the first line of flight they generated, I chose to break from the Western and settler's notion of postpositivist, linear, and linguistic interview practice. In the following section, I delineate the first line of flight that the walking methodology generated which informed how I (re)constructed my research interviews drawing from the work of Elizabeth St. Pierre, Chela Sandoval, Mirka Koro-Ljungberg, and postcolonial theorists.

\section{(Un)settling Methodology: Ziyyarah ${ }^{1}$}

Where, when is research? If we resist the impulse to normalize and regulate research (now we have it right!), will it be acceptable for each researcher to define her own categories, her own process - to define 'research' and 'science?' Can research be so situated (hasn't it always been?) and, if so, how will we know it's valid? How will we even know whether it's 'research?' (St. Pierre, 1997, p. 10)

Many scholars critiqued the linear and prescribed methods of qualitative research. For example, Elizabeth St. Pierre (1997) wrestled with categories such as methods, methodology, and data wherein she placed the data "under erasure" (p. 175). Moreover, working on the "verge of intelligibility" (St. Pierre, 1997, p. 176), she theorized different types of data: emotional, dream, and sensual data which invoked different research methods and analyses. The linearity of the postpositivist research process that maintains the logic of procedure and representation limits speculative methods (Springgay \&

\footnotetext{
${ }^{1}$ Ziyyarah: Arabic word that means a visit in which someone visits usually a friend, family member, or acquaintance at his/her house. The host usually offers food and/or drink and enjoy an informal setting of conversations.
} 
Truman, 2017b), "normalizes out thinking and doing" (Lather \& St. Pierre, 2013, p. 630), and creates a few paths for knowing and creating knowledge.

Furthermore, Koro-Ljungberg, in her book Conceptualizing Qualitative Research Methodologies without Methodology (2015), interrogates the postpositivist methodological approaches as being limiting. For example, the subject's verbal accounts of experiences and text as in transcribed interviews, are the main considerations for what counts as data within the postpositivist paradigm. Such view limits other considerations for data and marginalize other perspectives and sources of knowledge. Koro-Ljungberg (2015) argues that "data should not be taken for granted" and she calls on scholars to re/un/consider the definitions and role of data and view data as amorphous, uncertain, and shifting instead of reductionist, fixed, and "knowable." Nordstrom (2017) argues that radical thinking of data and the "shifting intersections among processes, people, objects, purposes and so on" resists the realist ontology that focuses solely on unitary and living beings (p. 1). Hence, she offers conventions or contingent meetings between these forces to rethink qualitative research practices (methods, data, etc.) beyond the reductionist views of postpositivist methodology.

Along the same lines, Sandoval (2000), motivated by the decolonizing methodologies, designed a method or technologies for emancipation and for creating social movements and identities for thinking about social activism. These technologies are necessary skills to read across cultures, identifying and consciously constructing ideology, decoding languages of resistance and/or domination. Such research endeavors appear to be limited within the school of thought of postpositivist Western research. In contrast, walking methodology builds on the possibilities presented by the previous arguments to open up the research practices for decolonizing methodologies and for the entanglement of the spacetimematter (Barad, 2017) in a postqualitative paradigm.

As I was thinking of my research methodology for my dissertation, I wrestled with finding the middle space between the reterritorialization and the deterritorialization forces (Nordstrom, 2017). How can I trouble the Western approach to interviewing? What approach to interviewing would be respectful of my participants' ways of knowing and making sense of the world? Wrestling with these questions, I found inspiration in Smith's (1999) argument for methodological approaches that

provoke revolutionary thinking about the roles that knowledge, knowledge production, knowledge hierarchies and knowledge institutions play in decolonization and social transformation. (Smith, 1999, p. xii)

Building on the aforementioned ideas and the readings of Manning (2016), I began thinking differently and intra-actively with my methods. What if I interviewed my participants in their intimate space, at home? How can I be inclusive of the other intensities that constitute the subject (i.e., language, familiar connections, culture, religion, etc.)? Why can't the interview be a dynamic space of negotiating the multiplicities of the subject and the entanglement of the space? Instead of interviewing my non- 
Western participants who were American Muslim teenagers in "a space", I (re)constructed the Ziyyarah, a postcolonial interview, where I and my participants shared a conversational session at their home (thus the term Ziyyarah which means "a visit" in Arabic). While interrogating the (re)production of power inequality, hierarchy, and detachment from context of postpositivist interviewing, within Ziyyarah interview, "there is no preestablished hierarchy, nor is there a preconstituted subject-position external to the event" (Manning, 2016, p. 29). In contrast with the postpositivist interviews that foster researcher/researched binary where the researcher has the power and assumes the role of all-knowing, Ziyyarah invites a shared sense-making and engagement in knowledge creation by the researcher, researched alongside their entanglement with the space they inhabit. Ziyyarah shifted my thinking of interviews and created a line of flight to create a "provisional space" (St. Pierre, 1997) that is a mixture of both striated and smooth spaces. By making conventions or "meetings" (Nordstrom, 2017) between participants' ways of knowing, culture, space, history, and beliefs, and interrogating the researcher/researched binary, Ziyyarah becomes an informal conversational methodological space that generates transgressive data.

\section{Second Line of Flight}

Walking, as a research, initially, emerged to the group as an "agitation" in which anxieties and uncertainty about what to do and how to do it continued to arise (Springgay \& Truman, 2017b). Walking, as a research, begged the question of the "how of research" (Truman \& Springgay, 2016, p. 259) that we, as doctoral students at the time, grappled with. How can walking as research create knowledge? How do we do walking research? What are the guidelines for the final "project" needed for course completion? Nonetheless, the whole group discussions after the walk and the readings (e.g., Truman \& Springgay, 2016) that situated the walks presented us with the potentialities and the actualities of walking as an embodied and sensory inquiry tool and rendered a different way of thinking of research beyond proceduralism. As our training entailed knowing what was ahead and lists of specific identifiable and measurable expectations, the thoughts of how, when, and what were inescapable. Statements of uncertainty about the potentialities and expectations of the walk surfaced up as we, the students who chose to call ourselves researchers, philosophers, and artists to denote the interdisciplinary making of our class, questioned the how and the what in research outside the normative and postpositivist approaches for research. These statements of uncertainty were evident in our class blog where we shared our thoughts, questions, and reflections on the course readings, events, and group walks. For example, one walker reflected on the first walk stating that "I find myself wondering how close to some (this?) utopian immersion into walking can we achieve?" (Walker 1, Walk 1). In a few blog posts, this uncertainty and perceived vagueness translated to frustration as class readings and walking methodologies deconstructed and interrogated our normative thinking and practices. Our inability to escape the stratified space of thought limited our perceptions of the relational multiplicity of the spacetimematter (Barad, 2017) that highlights the forces of space, time, and the materiality that shape a phenomenon such as human subjectivities and experiences. Nonetheless, we continued the walks alongside course readings and group discussions to explore the unfamiliar terrain of research to excavate the hidden layers of interactions in and within the spacetimematter. In the 
following section, I will detail the second line of flight that describes my experience with walking methodology as an embodied sensory and relational inquiry.

\section{Feel the muscles in your body}

\section{Feel the smooth whistling air on your skin}

Walk, breathe, listen, observe

The second walk, which I walked individually, was infused with an awareness of the embodied experience of walking. How do I walk or transport from one place to another? How does my brain orchestrate the muscles to walk harmoniously and subconsciously? How can the embodied experience of walking translate into research practice and create new knowledge? Those were some of the questions that stormed and whistled in my mind and (un)settled my thinking of my body and its interaction with the more-than-human world.

Walking Annesdale, which was a neighborhood I had never visited before the walks, impelled me to ponder and experience the aesthetics of the space (i.e., historic homes, cozy porches, high widely spread trees, etc.). Intrigued by the history of the space, I wondered how the neighborhood looked 100 years ago. What type of bodies were (dis)placed from the space and what body were given the privilege of being in the space? I listened to the sound of fall winds blowing, sensed the shy warm sun rays peeking through the clouds on my face shooting some warmth through my exposed skin, and heard the singing of the birds in what I remember it to be a pleasant walk. I heard the sound of dry leaves cracking under my feet inter-acting with the sound of the rubber in my tennis shoes pressing on the pavement. For a few moments, I spaced out in the space thinking through my body while recognizing the environment as a "world of fleshy beings with their own needs, claims, and actions" (Alaimo, 2010, p. 2). The interconnectedness between my human body, mind, and the environment in a more-than-human world engendered a relational experience of the walk.

After nearly 20 minutes, I felt pain in my right knee. How can I explain the pain to someone? How can someone else understand my experience with the pain? My thoughts, then, evolved around the embodied experience of the walk and provoked thoughts and insights particularly pertaining to individuals who are unable to employ the physicality of their body muscles to produce intended displacement. As I proceeded in my walk, I developed a sense of mindfulness about the physics of the movement entangled with the thought of the brain that renders the walk and transports the body. I walked in rhythm constantly spacing the space, stepping over a muddy pothole, gently moving upward the hill fearing a sudden fall, picking up the pace of my walk as I cross a busy street. The walk evolved into an experience of embodying the body, as a fascinating and complex machine and its sensory meetings with the thought and the space. While I examined the potentialities and actualities of my body movement, I constructed a new knowledge of what the body can do and what it cannot. But what if I cannot walk? Can I still move? This complex machine that allows and generates the physicality of walking can also disrupt and upset actions and imprison thoughts. But the incapacity of the body to enact displacement without assistance does not mean a total loss of movement but rather an absolute 
movement with zero displacement (Manning, 2009). The distinction that Manning (2009) makes between the displacement and the movement entails a virtual walking capacity of the body-walking of the brain. Hence, even abled-bodies are faced with challenges imposed by body senses and processed by the brain based on archived experiences. I am able to climb the hill, but my fear of falling or my past experience of falling while climbing the hill can disrupt my pace and halt my climb. The repertoire of our past experiences could hinder enacting certain movements and limit the creation of new experiences, as such.

Nonetheless, I realized that the interaction and the direct contact between the corporeality of the body and the more-than-human world generate new possibilities for activism and ethico-political consideration (Alaimo, 2010). Thinking with the movement across bodies and considering transcorporeality brings attention to material agency in which the body becomes entangled with the material, discursive, and textual (Alaimo, 2010). Human corporeality is charged with ideological consideration for particular types of people such as immigrants, women, indigenous people, people of color, and Muslims. As the race, gender, skin color, religion, and in certain instances the clothes individuals wear materialized within the more-than-human world, certain bodies are (dis)placed and deemed inferior. I felt my body's (dis)placement as I walked Annesdale. The on-foot perspective for me as a Muslim American rendered a sense of not belonging. The materiality of my headscarf ( $h i j a b$ ) I wore on my head positioned me as different within the Western norms of practices. Moreover, the materiality of the headscarf invoked a postcolonial dichotomy of us/them and insider/outsider. Infused with posthumanism theories, the embodied experiences presented possibilities for ethico-political engagement which I will elaborate on as the third line of flight generated from the walks.

\section{Third Line of Flight}

Though embodiment is an important aspect of walking research, Springgay and Truman (2017a) argue that this embodiment "needs to move beyond an individual and sensuous account of the body in space towards a different ethico-political engagement" (p. 4). Decentering human exceptionalism requires attending to the ethico-political practices of transmateriality (Springgay \& Truman, 2017a) to interrogate racialized practices and marginalization of minoritized population. An inspiring example of such an ethico-political engagement was Walking to the Laundromat which was created by Rebecca Conroy (n.d.) for Walking Lab.com. Walking to the Laundromat employed transcorporeality within walking methodology to interrogate capitalism and gendered labor practices that (dis)placed certain bodies as marginal and disposable. The idea of moving beyond the embodiment experience of the walking to attend the transmateriality of the walk with an ethico-political awareness engendered the third line of light that conceptualized walking within/ in a more-than-human world.

\section{Cross boundaries, overcome limits, think intra-actively}

Ulmer (2017) described posthumanism as a theoretical underpinning for walking research that examines boundaries, intersections, and openings through human and non-human interactions. Posthumanism situates the knowledge at the interconnectedness and the materialism of the context and creates 
openings for new possibilities for research and representation (UImer, 2017). Hence, the interconnectedness between the walking bodies and the socio-cultural context of the space was inevitable. During the third walk, as my knowledge of walking methodology evolved, I became engaged in relational and material inquiry of the walk which aimed at disrupting the normalized and privileged narratives of race, class, gender, and the politics of belongings. What race, gender, or religion is granted the privilege and who is deemed unworthy of the same privilege?

Alaimo (2010) argues that infusing research with trans theories (i.e., transcorporeality) generate methods for interrogating neoliberalism, capitalism, and postcolonial practices. Transcorporeality "underlines the extent to which the substance of the human is ultimately inseparable from 'the environment"' (p. 2). As an American immigrant Muslim female, walking through Annesdale and its unfamiliar streets and buildings, engendered a sense of being the "Other" and not belonging despite living in the city for over 20 years. I traveled back in time to the moment I first felt estranged arriving at the airport of Memphis to meet my husband 20 years ago. I stood out in the crowd with my headscarf, Middle Eastern accent, and brown skin color. With the spread of anti-Muslim rhetoric, my innocent experience of musing while walking became a liminal space in which walking is construed as what Solnit (2000) refers to as a "performance rather than transport" (p. 234). A walker's race, gender, skin color, religion, and culture become public; hence, possibilities of stereotypes and prejudices are inescapable. In my case, the materiality of my headscarf signaled and imposed my positionality as different and foreign. While I am walking within the space, I am also shoved to its margins and rendered an outsider. Nonetheless, for me, walking with my group resonated with Solnit's (2000) notion of walking in solidarity aligning the body and the hearts which alleviated feelings of alienation and fear and created new experiences and knowledge. This solidarity overcame invisible boundaries and blurred the razorsharp lines of liminality.

Furthermore, walking with the ecologies of the space examined boundaries and entanglement of the humans and the non-humans particularly for Memphis artists as the street murals, art designs, and graffiti "managed simultaneously [to] speak out against inhuman industry and racial neighborhood boundary and proclaim respect for Afro-centric culture, from a localized, feet-on-the ground outlook, just for those who walk" (Walker 2, walk 2). I have found Manning's (2009) idea of "the body's capacity to create experiential space-time" through movement and sensory interactions to be liberating (p. 65). In other words, my thought seemed to be given the freedom to wander while decentering human experiences to encompass body, movement, and them materiality of the space.

Evidently, the conversations and discussions shifted from examining the external and physical body movement and inner consciousness to become situated within the concept of the Anthropocene and in some instances the Capitalocene. For example, discussion of the human's impact on the environment and of the politics within interrogated city practices particularly by how "[g]entrified neighborhoods erect boundaries and present underserved people from re-entering the neighborhoods from which they were removed" (Walker 3, Walk 2). The city's neighborhoods past and history informed the walks and 
the data assemblages. For example, gentrification efforts in some neighborhoods such the Crosstown Concourse were presented "attempts to deploy notions of collective identity drawing on the history of the Sears' "alleged concerns for racial diversity and 'conscious capitalism" (Walker 4, walk 2). Additionally, maintaining the status of being historic was presented as a form of activism to "preserve and protect" the Central Gardens neighborhood from apartments, nursing homes, halfway dwellings and to remain "desirable residential neighborhood" (Walker 5, Walk 2, 3).

\section{Unravel, (un)settle, think with, within, and differently}

Springgay and Truman (2017b) argue that to unravel the postpositivist anthropocentric approaches of research which rest on objective reality, we need inventive practices. The method of walking the neighborhoods called attention to the affective, intra-active, and relational networks within the new materialist and posthumanist paradigms of thought rendering a type pf inventive practices that unravel the postpositivist research approaches. Over weeks of eventing, to borrow the term from Springgay and Truman (2017b), we, researchers, artist, and philosophers, used walking within and with the neighborhoods to (un)settle normalized practices and interrogate neoliberal segregation and gentrifications efforts. Working from the middle in the field of variation, walking the city of Memphis was a speculative eventing practice that invoked the posthumanism, transmateriality, and antimethodology thoughts with accountability to the material world and the entanglement of spacemattertime. Employing the concept of trans (i.e., trascorporeality and transmateriality) in understanding walking research attends to the interconnectedness between and within humans and non-humans where "place becomes a dynamic concept, interpenetrated by connections to other social and economic worlds" (Jones \& Evans, 2012, p. 2320).

Furthermore, drawing from the posthumanist theories, planning and proceeding with our walks rendered a new perspective to thinking differently with the spacetimematter (Barad, 2017), Western research tradition, and walking as an embodied experience. Many scholars thinking with animals, objects, things, elements, and theories "wonder how might research might become more than itself by adding new ways of thinking into methodology" such as collecting data through walking or extending the concept of transcorporeality to interrogate neoliberal practices (Ulmer, 2017, p. 841-842).

Not only did we interrogate research methods and postcolonial narrative within walking the city of Memphis, our walks also became infused with references to time and history and their intersections with space and matter. Haraway (2015) attended to the entanglement of the humans and non-human assemblage replacing the Anthropocene with the Chthulucene. The Chthulucene "entangles myriad temporalities and spatialities and myriad intra-active entities-in- assemblages-including the more-thanhuman, other-than-human, inhuman, and human-as- humus" (p. 160). For me walking, thinking of the Chthulucene, and learning became "truly present...as mortal critters entwined in myriad unfinished configurations of places, times, matters, meanings" (Haraway, 2016, p. 1). These thoughts decentered human experience, liberated my thinking and research practices, and brought attention to the 
assemblage of existences of humans, matter, affect, space, and time rendering equitable existence for all.

\section{References}

Alaimo, S. (2016). Exposed: Environmental politics and pleasures in posthuman times. Minneapolis, MN: University of Minnesota Press. https://doi.org/10.5749/minnesota/9780816621958.001.0001

Barad, K. 2007. Meeting the universe halfway: Quantum physics and the entanglement of matter and meaning. Durham, NC: Duke University Press. https://doi.org/10.1215/9780822388128

Braidotti, R. (2011).Complexity against methodological nationalism. In Nomadic Theory: The Portable Rosi Braidotti (pp. 209-238). New York, NY: Columbia University Press

Deleuze, G., \& Guattari, F. (1987). A thousand plateaus: Capitalism and schizophrenia. Minneapolis, MN: University of Minnesota Press.

Jones, P., \& Evans, J. (2012). Rescue geography: Place making, affect and regeneration. Urban Studies, 49(11), 2315-2330. https://doi.org/10.1177/0042098011428177

Haraway, D. (2015). Anthropocene, capitalocene, plantationocene, chthulucene: Making kin. Environmental Humanities, 6(1), 159-165. https://doi.org/10.1215/22011919-3615934

Haraway, D. (2016). Staying with the trouble: Making kin in the Chthulucene. Burham, NC: Duke University Press

Koro-Ljungberg, M. (2015). Reconceptualizing qualitative research: Methodologies without methodology. London, UK: SAGE Publications. https://doi.org/10.4135/9781071802793

Lather, P., \& St. Pierre, E. A. (2013). Post-qualitative research. International Journal of Qualitative Studies in Education, 26(6), 629-633. https://doi.org/10.1080/09518398.2013.788752

Manning, E. (2009). Relationscapes: Movement, art, philosophy. Cambridge, MA: MIT Press. https://doi.org/10.7551/mitpress/9780262134903.001.0001

Manning, E. (2016). The Minor Gesture. Durham, NC: Duke University Press. https://doi.org/10.1215/9780822374411

Nordstrom, S. N. (2017). Antimethodology: Postqualitative generative conventions. Qualitative Inquiry, 24(3), 215-226. https://doi.org/10.1177/1077800417704469

Sandoval, C. (2000). Methodology of the oppressed. Minneapolis, MN: Minnesota University of Minnesota Press.

Smith, L.T. (1999). Decolonizig methodologies: Research and indigenous peoples. Dunedin, FL: University of Otago Press

Solnit, R. (2000). Wanderlust: A History of Walking. New York, NY: Penguin Nooks.

Springgay, S., \& Truman, S. E. (2017a). A transmaterial approach to walking methodologies: Embodiment, affect, and a sonic art performance, Body \& Society, 23(4), 27-58. https://doi.org/10.1177/1357034X17732626

Springgay, S., \& Truman, S. E. (2017b). On the need for methods beyond proceduralism: Speculative middles, (in)tensions, and response-ability in research. Qualitative Inquiry, 24(3), 203-214. https://doi.org/10.1177/1077800417704464 
St. Pierre, E. A. (1997). Methodology in the fold and the irruption of transgressive data. International Journal of Qualitative Studies in Education, 10(2), 175-189. https://doi.org/10.1080/095183997237278

Truman, S., \& Springgay, S. (2016). Propositions for walking research. In Burnard, P., Mackinlay, E., \& Powell, K. A. (Eds.). The Routledge International Handbook of Intercultural Arts Research (259267). New York, NY: Routledge.

Ulmer, J. B. (2017). Posthumanism as research methodology: Inquiry in the anthropocene. International Journal of Qualitative Studies in Education, 30(9), 832-848.

https://doi.org/10.1080/09518398.2017.1336806 